\title{
Players' technical and physical performance profiles and game-to-game variation in NBA
}

\author{
Shaoliang Zhang ${ }^{a, b, c}$ (D), Alberto Lorenzo ${ }^{a}$, Miguel-Angel Gómez ${ }^{a}$ (D) Hongyou Liu ${ }^{b}$ (D), \\ Bruno Gonçalves ${ }^{c}$ (iD) and Jaime Sampaioc (iD)
}

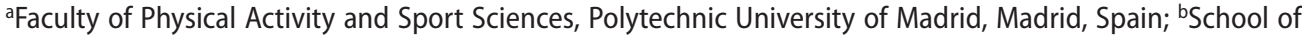
Physical Education and Sports Science, South China Normal University, Guangzhou, China; 'Research Center in Sports Sciences, Health Sciences and Human Development, CIDESD, CreativeLab Research Community, Vila Real, Portugal

\begin{abstract}
The aim of this study was to (i) identify technical and physical performances of basketballers according to playing position in strong and weak teams, and (ii) describe variability in game-togame performance according to game outcome, location, quality of teams and opposition. Performance-related variables of all the 699 matches of regular season 2015-2016 in the National Basketball Association were analysed. All the comparisons were performed using magnitude-based inferences. As could be expected, results showed that technical and physical performances differed between players of strong and weak teams. In technical aspect, forwards and centres from strong teams made more three-point field goals, but fewer two-point field goals, than their counterparts from weak teams. Interestingly, forwards and guards from strong teams covered shorter distances and lower speeds than their peers from weak teams. In addition, the threepoint field goals made and attempted presented high variability. Game location generally had no significant impact on the variability of players' performance. Guards exhibited relatively lower variability in technical and physical variables in comparison with players from other positions. Exploring the difference and variability of technical and physical performances of basketballers allows fine-tuning of practice and game plans in order to build up optimal winning strategies.
\end{abstract}

\section{ARTICLE HISTORY}

Received 16 May 2017

Accepted 5 July 2017

\section{KEYWORDS}

Basketball; game statistics; performance variability; situational variables

\section{Introduction}

The process of preparing basketball teams at the highest standard of competition is complex and depends upon the interactions of technical, tactical, physical, psychological and physiological characteristics of available players (Csataljay, O’Donoghue, Hughes, \& Dancs, 2009; Sampaio et al., 2015). Currently, performance analysis provides information on both the physical activity, the technical and tactical responses of each player and team during the games (Hughes \& Franks, 2004). The available research has clarified the relationship between players' technical performances and game final outcome (Gómez, Lorenzo, Ortega, Sampaio, \& Ibáñez, 2009; Sampaio, Drinkwater, \& Leite, 2010; Sampaio, Janeira, Ibáñez, \& Lorenzo,

CONTACT Hongyou Liu szu.youyou@hotmail.com 
2006). For instance, defensive rebounds and two-point field goals would be commonly regarded as discriminant variables between winning and losing teams (Csataljay et al., 2009; Gómez, Lorenzo, Sampaio, Ibáñez, \& Ortega, 2008; García, Ibáñez, Gómez, \& Sampaio, 2014). However, contrasting winners' and losers' performance can only provide limited information for teams' success at a given instant, because successful teams can also lose some games and vice-versa. Therefore, some studies have used different methods to evaluate and compare the quality of teams and their opponents, such as multi-criteria assessing methods like TOPSIS and AHP (Dadelo, Turskis, Zavadskas, \& Dadeliene, 2014; Kiani Mavi, Kiani Mavi, \& Kiani, 2012) or cluster analysis (Marcelino, Mesquita, \& Sampaio, 2011; Sampaio, Drinkwater, et al., 2010). Besides, teams' quality has either been subjectively categorised as "successful" or "unsuccessful" according to their standings or winning percentage within a particular tournament (Gómez, Ibáñez, Parejo, \& Furley, 2017; Ibáñez et al., 2008; Pollard \& Gómez, 2007; Sampaio, Ibáñez, Lorenzo, \& Gómez, 2006) or classified as "strong" or "weak" and "top half" or "bottom half" based on symmetric division of end-of-season classification (Doğan, Işik, \& Ersöz, 2016; Sampaio, Lago, Casais, \& Leite, 2010). However, there is less available research about exploring the difference of technical and physical performances of players according to the specific position between different levels of teams. Therefore, the development of technical and physical performance profiles considering team quality would be necessary to reveal new trends and also to provide useful information to support coaching staffs tailoring optimal strategies and training plans.

Another important issue that has been given limited attention is the concept and interpretation of the game-to-game variation of the technical and physical performances of basketball players (Mateus et al., 2015; Pinilla Arbex, Pérez Tejero, Van Biesen, \& Vanlandewijck, 2015). As a matter of fact, one of the most common features of human movement is its variability. It is suggested that better performances can be achieved when variability increases to a point of higher instability, followed by an automatic switch to a new and more stable movement pattern with less variability (Stergiou \& Decker, 2011; Thelen, 1995). In other words, biological systems self-organise according to environmental, biomechanical and morphological constraints to find the most stable solution for producing a given movement (Clark \& Phillips, 1993; Hamill, van Emmerik, Heiderscheit, \& Li, 1999). Thus, increased variability in a movement pattern generally indicates loss of stability, while decreased variability generally demonstrates a highly stable behaviour (Stergiou \& Decker, 2011). In fact, movement execution will inevitably give rise to movement variability because motor output (motor commands, muscle contractions or muscle torques) is inherently variable (van Beers, Haggard, \& Wolpert, 2004). In order to more effectively execute movement pattern in a given environment, decreasing variability seem to be commonly regarded as the best ideal solution (Newell \& Corcos, 1993; Stergiou, Harbourne, \& Cavanaugh, 2006). In team sports, players maintain stable performance and effectively perform technical and tactical strategies on the court, leading to the success of the teams in a long-term performance (Liu, Gómez, Gonçalves, \& Sampaio, 2016).

In particular, the basketball games can be considered as complex, unstable, adaptive and dynamic systems in which players try to keep lower variability of their own attacking and defending balance and to destabilise the balance of the opposition (Guerra et al., 2013; Oliver, 2004). Several situational variables such as game outcome, game location, quality of opposition or team quality, are considered as very important variables that influence individual and collective performances (García, Ibáñez, Martinez De Santos, Leite, \& Sampaio, 2013; Gómez 
et al., 2008; Ibáñez, Sampaio, Sáenz-López, Giménez, \& Janeira, 2003; Lorenzo, Gómez, Ortega, Ibáñez, \& Sampaio, 2010). For example, due to the effect of crowd factors, learning/ familiarity factors, travel and rule factors on players' performance (Carron, Loughhead, \& Bray, 2005), players are likely to display lower variability in technical and physical performances in home games than away games. In fact, Sampaio, Ibáñez, Gómez, Lorenzo, and Ortega (2008) have identified that the game context, such as game location, has a huge impact on performance of basketball players from different positions. However, there is still a lack of understanding for the variability of players' performances from different positions under different situational variables. Consequently, analysing the variation of players' performances from different positions incorporating possible influences of different environmental constrains (game contextual variables) would make a very important contribution to a better understanding of the basketball game (Mateus et al., 2015).

Based on previous considerations, the aims of the current study were to compare the between-player differences in technical and physical performances of strong and weak teams according to players' specific field positions and, to explore the within-player gameto-game variation of technical and physical performances taking consideration of four contextual variables, i.e. team and opposition quality, match outcome and match location. We hypothesised that there may be the differences in terms of game statistics and physical aspects for players from different positions between strong and weak teams and game-togame variation in technical and physical aspects across different playing positions would be influenced by situational variables.

\section{Methods}

\subsection{Sample}

Archival data were obtained from open-access official NBA records during the 2015-2016 regular season (available at https://stats.nba.com). A total of 699 games were selected based on the balance score inclusion criteria during the regular season, i.e. games that ended with final score differences equal to or less than 10 points (Ferreira, Volossovitch, \& Sampaio, 2014). The game-related statistics were transformed to per-minute statistics (original statistics/min $\times 40$ ) according to players' game duration on the court (Kubatko, Oliver, Pelton, \& Rosenbaum, 2007). The players with less than 500 min played in the whole season were excluded from the sample, as those players' transformed data were regarded as unreliable per-minute statistics (Kubatko et al., 2007). In addition, the players who played only one game or less than five minutes were also excluded from the sample (Sampaio, Janeira, et al., 2006), which limited the sample to 354 players with 12,724 performance records. Players were divided by three different categories based on playing positions: Guards ( $n=155$ players, observations $=5453)$, Centres $(n=59$, observations $=2148)$ and Forwards $(n=140$, observations $=5123$ ). In order to precisely make sure the players' position, playing certain position was determined by referring to the NBA official website (https://stats.nba.com).

\subsection{Data source and validity}

In order to test the validity of data-sets, a sub-sample of 20 games (final score differences equal to or less than 10 points) were randomly selected and observed by two experienced 
analysts (basketball coaches with more than 5 years of experience in basketball performance analysis). The results were contrasted with the gathered data in the website and perfect Intra-class Correlation Coefficients (ICC $=1.0$ ) were obtained for free throws, two-and three-pointers (both made and attempted), offensive and defensive rebounds, turnovers, steals, blocked shots, personal fouls, passes made. For the assists and touches, the results were lower, but still very acceptable as valid (ICC $=0.91$ ). There was a formal approval of all procedures from the Local Institution of Research Review Board.

\subsection{Variables}

A total of 17 game actions and events were selected as variables in the analyses (Mateus et al., 2015; Sampaio et al., 2015). Analysed variables included non-tracking variables, tracking variables and situational variables per game.

\subsubsection{Non-tracking variables}

- Two-Pointers made (2PM): The number of two-point field goals that a player or teams has made.

- Two-Pointers attempted (2PA): The number of two-point field goals that a player or teams has attempted.

- Three-pointers made (3PM): The number of three-point field goals that a player or teams has made.

- Three-pointers attempted (3PA): The number of three-point field goals that a player or teams has attempted.

- Free Throws made (FTM): The number of free throws that a player or teams has successfully made.

- Free Throws attempted (FTA): The number of free throws that a player or teams has taken.

- Offensive Rebounds (OREB): The number of rebounds that a player or teams has collected, while they were on offence.

- Defensive Rebounds (DREB): The number of rebounds that a player or teams has collected, while they were on defence.

- Assists (AST): An assist occurs when a player completes a pass to a teammate that directly leads to a made field goal.

- Turnovers (TOV): A turnover occurs when the teams on offence loses the ball to the defence.

- Steals (STL): A steal occurs when a defensive player takes the ball from a player on offence, causing a turnover from offensive players.

- Blocked Shots (BLK): A block occurs when an offensive player attempts a shot, and a defensive player tips the ball, blocking their chance to score.

- Personal Fouls (PF): The total number of fouls that a player or teams has committed.

- Touches (TCHS): The number of times a player touches and possesses the ball during the game.

- Passes Made (PASS): The total number of passes a player made during the game. 


\subsubsection{Tracking variables}

- Distance Run (DIST): The total distances in miles that a player covered, while on the court.

- Average Speed (SPD): The average speed in miles per hour of all movements (springing, jogging, standing, walking, backwards and forwards) by a player, while on the court.

\subsubsection{Situational variables}

- Quality of the team and opposition. The teams that entered into the play-off season were defined as strong teams/oppositions and the teams that did not enter into the next phase were classified as weak teams/oppositions (Doğan et al., 2016; Ibáñez et al., 2008; Sampaio, Lago, et al., 2010).

- Match outcome (win and lose).

- Match location (home and away).

\subsection{Statistical analysis}

Records were screened for univariate outliers (cases outside the range Mean $\pm 3 \mathrm{SD}$ ) and distribution was tested in order to carry the inferential analysis (Kerlinger \& Pedhazur, 1973). The first phase was to set-up the performance profiles of players between strong and weak teams using profiling techniques (Butterworth, O'Donoghue, \& Cropley, 2013; O'Donoghue, 2005). Count values of the 17 performance-related game actions and events of all players were transformed into standardised scores (Z-Score, Z) and were unified into the same scale by the formula “ $\mathrm{T}=10 \mathrm{Z}+50$ ” (O’Donoghue, 2013). Using median to compare performances of all players and different position players (i.e. guards, centres and forwards) and represented by plotting into radar charts (Liu et al., 2016).

The second phase was to explore the variation of players' game performance from different positions under four different situational variables (i.e. teams and opposition quality, match outcome and match location). The within-player game-to-game variation was measured by the coefficient of variation $(\mathrm{CV})$ of each game action or event. The differences of variation in performance were compared for (a) winning games and losing games, (b) home games and away games (c) strong teams and weak teams, and (d) strong opposition and weak opposition. For example, if one player performed in 50 games at home and 45 games away, the CV was calculated separately for each condition and compared. In order to calculate the within-player CV ((standard deviation/mean) $\times 100 \%)$, only the players who played at least two entire matches were selected in each game context. When the mean of an action or event was 0 (e.g. 0 three-point field goals made in 20 games), the $\mathrm{CV}$ of this single action or event was defined as a missing value. The software used for these calculations was IBM SPSS Statistics for Windows (Armonk, NY: IBM Corp.) and the radar charts were drawn in the Microsoft Excel (Redmond, Washington: Microsoft). Comparisons of performance profile and variation of match performance were carried using the spreadsheet developed by Hopkins (2007). Non-clinical magnitude-based inferences were applied and were evaluated using the smallest worthwhile difference, calculated by 0.2 times the standardisation estimated from between-subject standard deviation. For the comparison of players' performance profile and variation of match performance, the $90 \%$ 
confidence intervals were used to make the inferences (Hopkins, 2007). Magnitudes of clear differences were assessed as follows: $<0.20$, trivial; $0.20-0.60$, small; $0.61-1.20$, moderate; 1.21-2.0, large; $>2.0$, very large (Batterham \& Hopkins, 2006). Differences were defined as unclear when the confidence limits for the effect size include both substantial positive and negative values ( $\pm 0.2 \times$ standardisation) (Hopkins, Marshall, Batterham, \& Hanin, 2009). Likelihood of the magnitude to be clear was defined as follows: $<0.5 \%$, most unlikely; $0.5-5$, very unlikely; $5-25 \%$, unlikely; $25-75 \%$, possibly; $75-95 \%$, likely; $95-99.5 \%$, very likely; $>99.5 \%$, most likely (Hopkins et al., 2009).

\section{Results}

The comparison of performance variables between players from strong and weak teams can be found in Table 1 and Figure 1. There were some clear differences in terms of technical variables in centres and forwards position and physical variables in guards and forwards position between strong teams and weak teams.

The differences were clear in physical variables when comparing all players together; players from strong teams covered shorter distances (possibly small difference; ES $=0.21$ ) and lower speeds (possibly small difference; $E S=0.20$ ) than players from weak teams. The comparisons of players from different positions between strong and weak teams showed different results. Firstly, there were main differences in physical variables for guards between strong and weak teams. Guards from strong teams covered less distances (most likely small difference; ES = 0.28) and lower speeds (very likely small difference; ES = 0.27). Secondly, centres presented the biggest difference in terms of shooting ability. Centres from strong teams made less two-point field goals (likely small difference; ES $=0.25$ ) and attempted (likely small difference; ES $=0.24$ ), but made more three-point field goals (very likely small difference; ES = -0.46) and attempted (most likely moderate difference; ES = -0.73) comparing to their peers from weak teams. Finally, there were clear differences for forwards in technical and physical variables between strong and weak teams. In technical aspect, forwards from strong teams shot more three-point field goals (possibly small difference; $\mathrm{ES}=-0.20$ ) but fewer in two-point field goals (possibly small difference; ES $=0.21$ ). In physical aspect, forwards from strong teams run less distances (very likely small difference; $\mathrm{ES}=0.25$ ) and kept lower speeds (likely small difference; ES $=0.24$ ) comparing to their counterparts from weak teams.

The comparison on the difference of within-player game-to-game variation of technical and physical performances in different positions under different situational variables is presented (in Tables 2 and 3 and Figure 2).

Three-point field goals made (3PM) and attempted (3PA) were the most unstable technical game actions that showed substantial differences in variation in all the four situational contexts (Figure 2). Almost all of performance variables of players from different positions presented lower variation between home game and away game, and only personal fouls showed higher variation, in forwards position (possibly small difference; $E S=-0.26$ ), and in centres position (possibly small difference; $E S=-0.20$ ). Additionally, guards presented lower variability in technical and physical performances when comparing with players from different positions, because guards not only showed lower variation between home game and away game but also had same trend when facing with different levels of opposition (strong and weak opposition). 


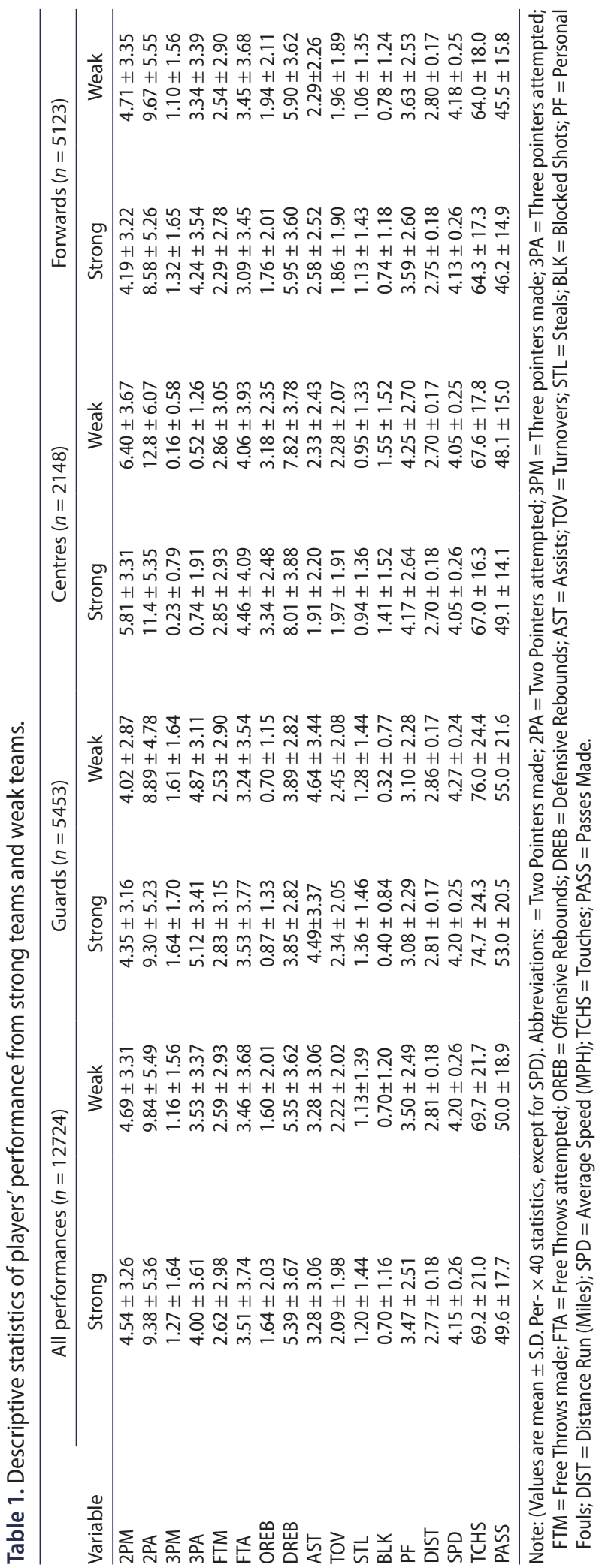


All players

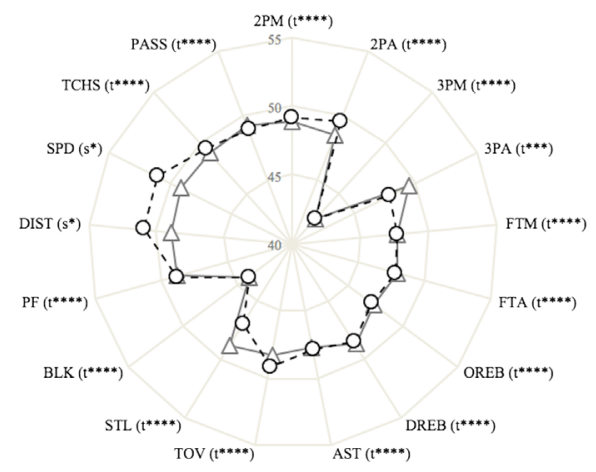

Forwards

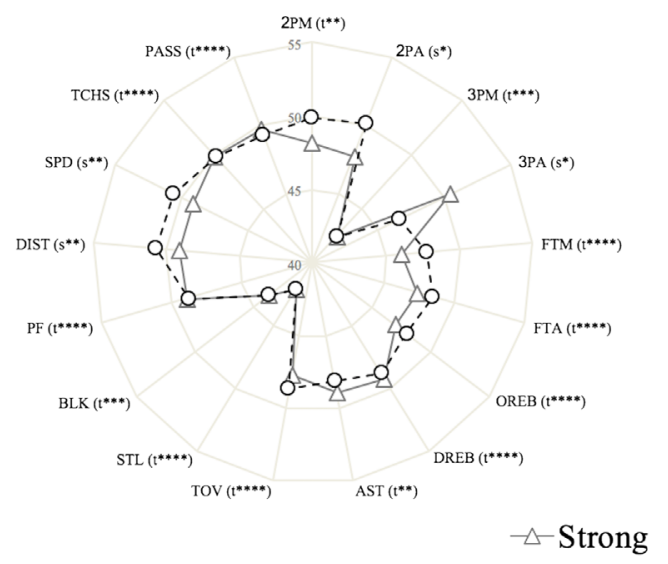

Guards

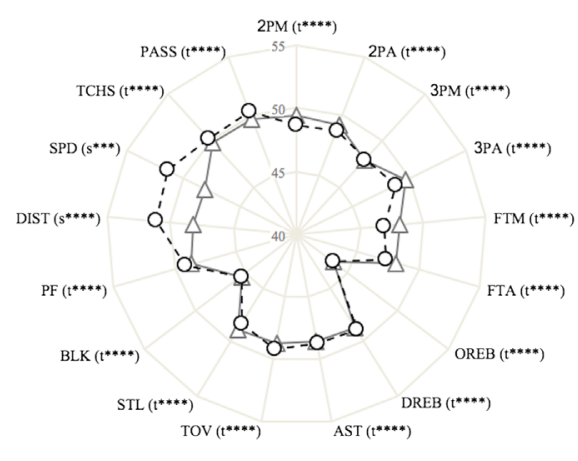

Centers

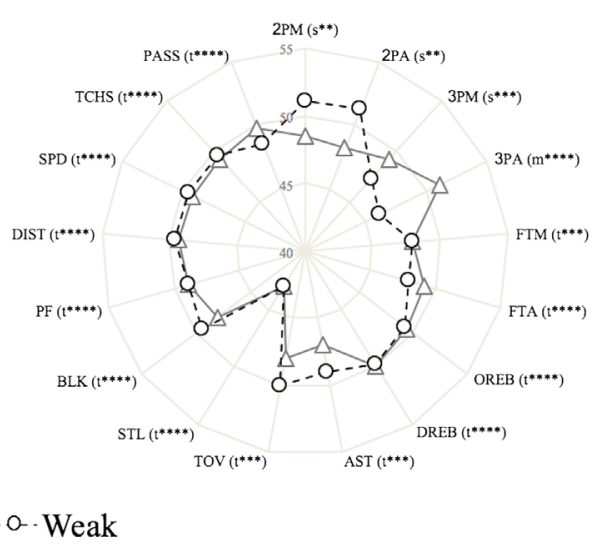

Figure 1. Comparison of the performance profiles of overall and different position's players from strong and weak teams.

Notes: Letters in parentheses denote the magnitude: $\mathrm{t}=$ trivial; $\mathrm{s}=\mathrm{small} ; \mathrm{m}=$ moderate; $\mathrm{I}=$ large. Asterisks indicate the likelihood for the magnitude of the true difference in means as follows: ${ }^{*}$ possible; ${ }^{* *}$ likely; ${ }^{* * *}$ very likely; ${ }^{* * * *}$ most likely.

\section{Discussion}

The aim of the present study was to (i) identify the difference of technical and physical performance variables for basketball players in the different positions between strong teams and weak teams, and (ii) explore the variability of players' performance across different playing positions when considering four different situational variables (i.e. game outcome, game location, team quality and quality of opposition). The previous basketball studies have clearly stated the influence of situational variables (Gómez, Lorenzo, Ibanez, \& Sampaio, 2013; Gómez, Prieto, Perez, \& Sampaio, 2013), playing positions (Sampaio et al., 2008; Sampaio, Janeira, et al., 2006) and performance variability (Mateus et al., 2015; Pinilla Arbex et al., 2015) as explanatory factors on teams' and players' performances. Accordingly, the current findings may enhance the importance of some variables when analysing the players' performances. Our results allow supporting the previous hypothesis that the players from strong teams, especially in guards and forwards position, covered shorter distances and lower 


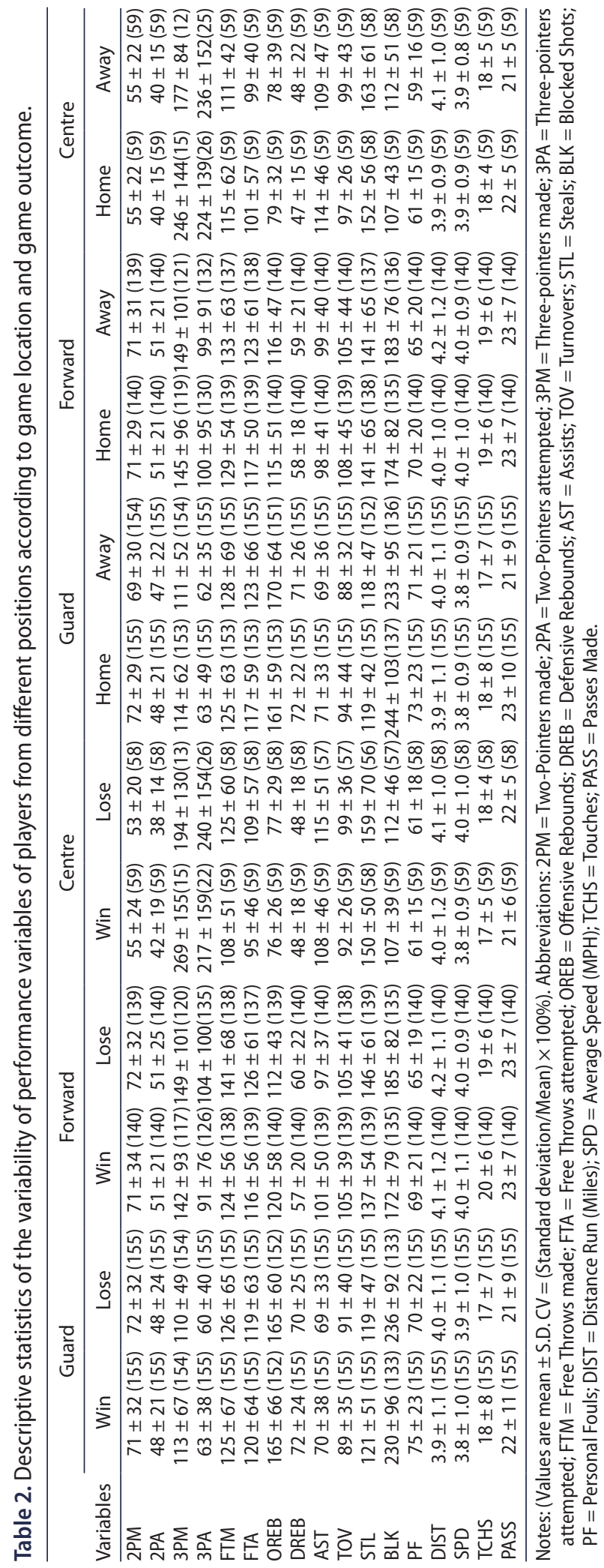




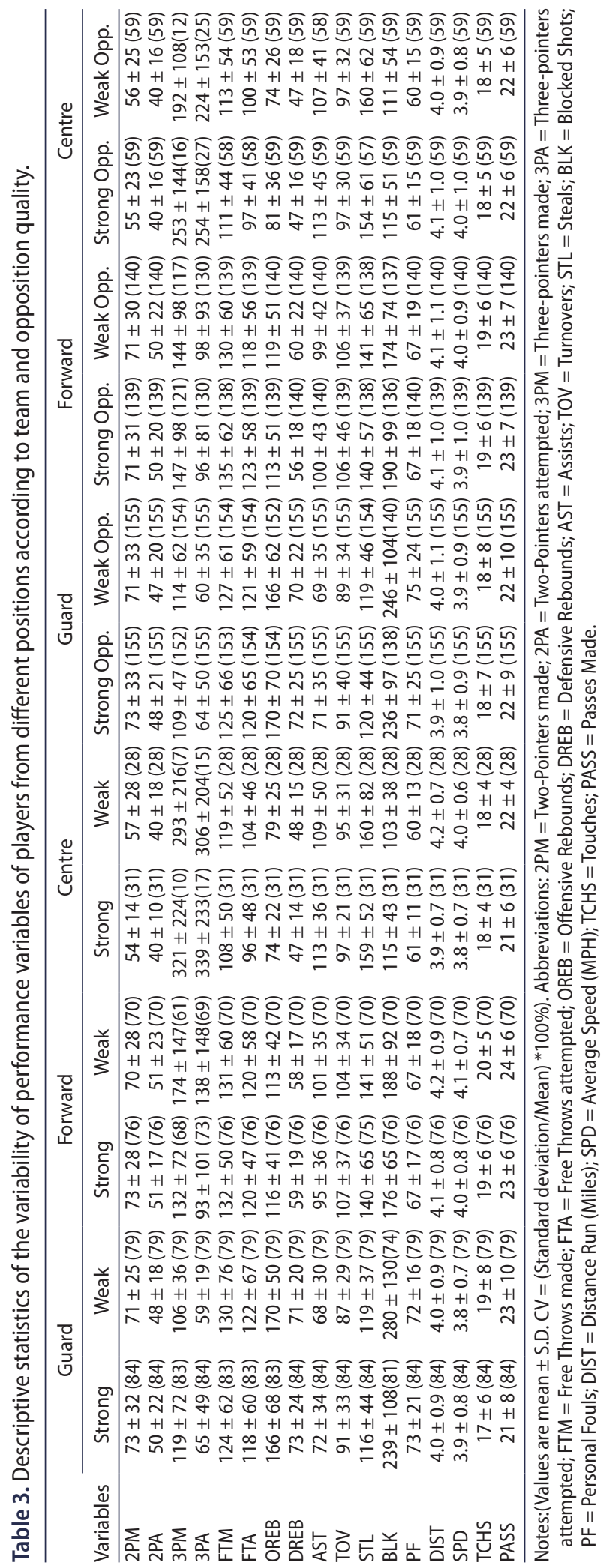



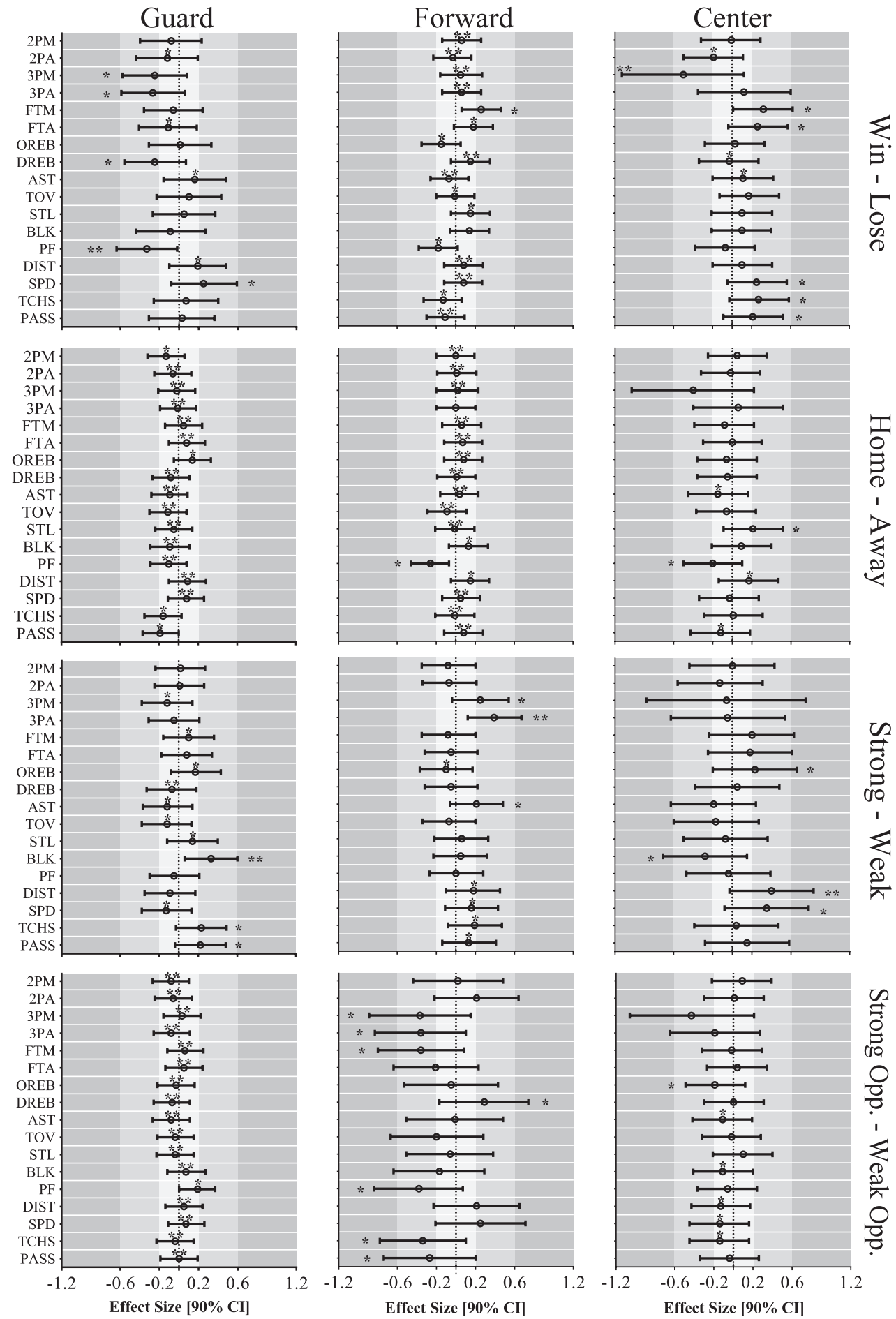

$\square$ Trivial

Effect Size $[90 \% \mathbf{C I}]$

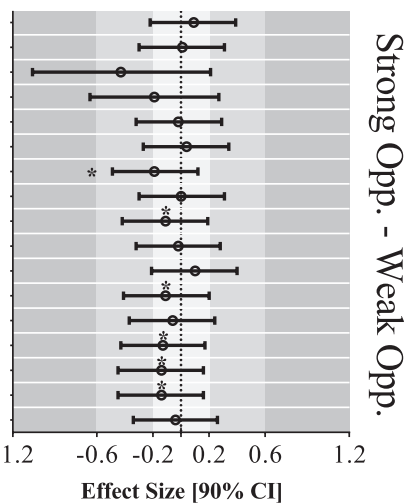

Moderate

Figure 2. Effect sizes of differences in mean of $\mathrm{CV}$ of each match action or event of (a) players in winning games and in losing games; (b) players playing at home and playing at away; (c) players from strong teams and weak teams; (d) players playing against strong teams and weak teams.

Notes: Asterisks indicate the likelihood for the magnitude of the true differences in mean as follows: *possible; * ${ }^{*}$ likely; ${ }^{* * *}$ very likely; ${ }^{* * *}$ most likely. Asterisks located in the trivial area denote for trivial differences. 
speeds, and centres and forwards from strong teams have better performance in three-point field goals than their counterparts from weak teams. Situational variables generally have an impact on game-to-game variation across different playing positions, but game location had no significant impact on performance variability of the players from different positions.

Firstly, when comparing with the difference of all players between strong teams and weak teams, our results indicated that players from strong teams covered shorter distances and lower speeds than their counterparts from weak teams. The previous study has identified that seasonal variation of the game events and actions was likely to depend on team quality because the best teams had the best players in training and game environments, which had an impact on game performances (Sampaio, Drinkwater, et al., 2010). Moreover, Sampaio, Drinkwater, et al. (2010) have identified strong teams outperform weak teams in terms of two-point field goals and passes, which means that best players from strong teams possibly get better control of the game pace and utilise more passes to complete technical and tactical strategies instead of covering more distance. This is possibly a result of having higher quality performers that take more informed decisions on when and where to run in offence and defence; therefore, those players possibly covered shorter distances at lower average velocities to reach their destinations (Sampaio et al., 2015).

Furthermore, our performance profiles also identified differences in the technical and physical demands of players from different playing positions. Previous studies have presented substantial differences for players fitness in a different position in terms of height (Cormery, Marcil, \& Bouvard, 2008; Sallet, Perrier, Ferret, Vitelli, \& Baverel, 2005), anthropometric features and body composition (Ostojic, Mazic, \& Dikic, 2006; Tomovic, Batinic, Saranovic, \& Antic, 2016), aerobic and anaerobic capacity (Hoffman, Epstein, Einbinder, \& Weinstein, 1999), speed and distances covered (Tsitskaris, Theoharopoulos, \& Garefis, 2003), agility (Alemdaroğlu, 2012), muscular strength (Willoughby \& Simpson, 1996), and heart rate variability (Paul \& Garg, 2012). Although these studies have provided important information on the fitness of guards, forwards and centres, to date, the difference on the physical aspects of the specific individual roles are not available between strong and weak teams. Our study found that guards and forwards showed small differences in physical variables between strong and weak teams. Specifically, guards and forwards from strong teams covered shorter distances and lower speeds than those from weak teams. As stated before, strong teams can effectively perform tactical strategies by passing and shooting instead of running too much during the game. In fact, in basketball games, guards and forwards mainly play the most important role in shooting and passing, because guards are in charge of organising the attacking process, and dominate passing and ball dribbling skills (particularly in 1 vs. 1 and screens situations) and forwards are responsible for shooting from long and medium distances and play an important role during fast break situations (either shooting or passing) (Courel-Ibáñez, McRobert, Toro, \& Vélez, 2017). However, there was a trivial difference when comparing with centres between strong and weak teams. In fact, Abdelkrim, Chaouachi, Chamari, Chtara, and Castagna (2010) found that guards and forwards spent a similar percentage of time performing high-intensity movements compared with centres (17.1\%, 16.6\%vs. 14.7\%, respectively). Miller and Bartlett (1994) also identified that centres spent more time stationary and less get involved in significantly high-intensity movements in comparison with guards and forwards during the game. Thus, these seem to be the reason that centres between strong and weak teams presented trivial differences in physical variables in comparison with guards and forwards. 
Sampaio, Lago, et al. (2010) and Ibáñez et al. (2008) have suggested that strong teams in the overall standings were the most effective at scoring points. Specifically, the effect of both two- and three-point field goals shooting was identified as "trivial" between strong and weak teams. Indeed, our results also demonstrated that there were small and moderate differences in terms of two- and three-point field goals for players in centres and forwards position between stronger and weaker teams. The previous studies of Fotinakis, Laparidis, Karipidis, and Taxildaris (2002) have suggested that one of the main characteristics of the NBA league is the use of 1-on-1 situations to solve the possessions with the centre players close to the basket. This is a specific characteristic of the athleticism of the NBA players that allow them to shoot near the basket and make dunks with a higher rate of effectiveness (Erculj \& Strumbelj, 2015). However, what is interesting about our findings is that centres and forwards from strong teams shot more three-point field goals, but fewer two-point field goals, than their counterparts from weak teams. In fact, the importance of three-point field goals reflects the gameplay based on inside-outside passes that create open space for shooting and 1-on-1 situations (Gómez, Gasperi, \& Lupo, 2016). Moreover, our results seem to imply that the future development of basketball games will need more skilled and versatile players, which means that players not only perform tasks at their primary position and would satisfy performance criteria on two or even more playing positions (Trninić, Papić, Trninić, \& Vukičević, 2008). For example, centres and forwards can create more space playing in the paint zone, and also create danger out of the three-point line.

Analyses on the game-to-game variation of individual players' technical and physical actions can get a further understanding of the game performance when considering effects of contextual variables (i.e. team and opposition quality, match outcome and match location). A recent study of Mateus et al. (2015) identified three-point field goals made and attempted were un-ideal performance variables to discriminate the variability of the players from the specific position. Indeed, our results also found that three-point field goals made and attempted were only technical game actions that displayed high game-to-game variation in all situational contexts. The higher variability in three-point field goals may be affected by the diversity of the position-specific (Mateus et al., 2015) and similar attributes players with different and specific roles on the court (Carter, Ackland, Kerr, \& Stapff, 2005; Sampaio, Janeira, et al., 2006). Furthermore, shooting distance may also have an impact on the variability, because long-range shots displayed greater variation than short-range shots (Miller, 2002; Robins, Wheat, Irwin, \& Bartlett, 2006).

Previously, game location was regarded as an important factor influencing both offensive and defensive performances of basketball (Carr, 2015; Gómez \& Pollard, 2011; Pollard \& Gómez, 2013; Sampaio et al., 2008). Specifically, the available research has identified that players playing away get worse field goal percentages, less defensive rebounds and more committed fouls than playing at home (Sampaio \& Janeira, 2003). By contrast, the present research identified that personal fouls were only game actions that showed greater variation when playing away than when playing at home. It is possible that players committed more fouls and presented higher variation in personal fouls in order to overcome game unexpected factors (e.g. more aggressive techniques and tactics from opposition, negative psychological and behavioural states, crowd pressure, less protection by the referees) in away games (García et al., 2014; Mateus et al., 2015). However, those influencing factors may gradually decrease in the future with the development of basketball game, because our results are in line with the previous results that showed that game location generally has a 
little impact on the variability of players' performance as opposed to our assumption in the introduction (Mateus et al., 2015).

Guards exhibited relatively lower variability in technical and physical variables in comparison with players from other positions under four situational variables. The main reason would be that in the NBA league guards are the central role for ball distribution especially in game control, ball handling and controlling the game rhythm, passing and organising offensive tactics and keeping higher long-range shooting ability (Fewell, Armbruster, Ingraham, Petersen, \& Waters, 2012). Managers and coaching staffs often supervise and control guards' physical load in the regular season in order to maintain stable performance and avoid sport injuries. The second reason would be that travel had an influence on players' performance in NBA owing to the lack of time for physical recovery (Steenland \& Deddens, 1997). However, guards might be rarely influenced by this factor. It is possible that they can quickly recover optimising physical situation due to smaller and lighter body features (Abdelkrim et al., 2010; Sallet et al., 2005).

\section{Conclusion}

The current study indicated that players (especially in guards and forwards position) from strong teams covered less distances and lower speeds than players from weak teams, possibly because strong teams are characterised by better tactical discipline and that can imply less high-intensity effort. For instance, players from strong teams do not need constantly quick responses to recover the defensive position or to force the final actions during attacking ball possessions. What is more, coaches should develop shooting ability of forwards and centres in out of three-point line or select players with this ability, because players (especially in centres and forwards position) from strong teams have a significant advantage over their peers from weak teams in three-point field goals. Finally, game location had no significant impact on the variability of players' performance, but it is worth noting that three-point field goals show higher variation when controlling for different situational variables. These findings would be used to optimise preparation for individual player, leading to improve game performances of the players and teams.

\section{Acknowledgements}

Project NanoSTIMA: Macro-to-Nano Human Sensing: Towards Integrated Multimodal Health Monitoring and Analytics, NORTE-01-0145-FEDER-000016.

\section{Disclosure statement}

No potential conflict of interest was reported by the authors.

\section{Funding}

The work was supported by the China Scholarship Council (CSC) from the Ministry of Education of P.R. China under Grant [(2015) 3022]; Fundo Europeu de Desenvolvimento Regional (FEDER) NORTE 2020. 


\section{ORCID}

Shaoliang Zhang (iD http://orcid.org/0000-0002-0543-7135

Miguel-Angel Gómez (iD) http://orcid.org/0000-0002-9585-3158

Hongyou Liu (D) http://orcid.org/0000-0003-4341-672X

Bruno Gonçalves (D) http://orcid.org/0000-0001-7874-4104

Jaime Sampaio (iD http://orcid.org/0000-0003-2335-9991

\section{References}

Abdelkrim, N. B., Chaouachi, A., Chamari, K., Chtara, M., \& Castagna, C. (2010). Positional role and competitive-level differences in elite-level men's basketball players. Journal of Strength and Conditioning Research, 24, 1346-1355.

Alemdaroğlu, U. (2012). The relationship between muscle strength, anaerobic performance, agility, sprint ability and vertical jump performance in professional basketball players. Journal of Human Kinetics, 31, 149-158.

Batterham, A. M., \& Hopkins, W. G. (2006). Making meaningful inferences about magnitudes. International Journal of Sports Physiology and Performance, 1, 50-57.

Butterworth, A., O’Donoghue, P., \& Cropley, B. (2013). Performance profiling in sports coaching: A review. International Journal of Performance Analysis in Sport, 13, 572-593.

Carr, J. (2015). The Home-court advantage effect in NBA basketball. Ottawa, Ontario: University of Ottawa.

Carron, A. V., Loughhead, T. M., \& Bray, S. R. (2005). The home advantage in sport competitions: Courneya and Carron's (1992) conceptual framework a decade later. Journal of Sports Sciences, 23, 395-407.

Carter, J., Ackland, T., Kerr, D., \& Stapff, A. (2005). Somatotype and size of elite female basketball players. Journal of Sports Sciences, 23, 1057-1063.

Clark, J. E., \& Phillips, S. J. (1993). A longitudinal study of intralimb coordination in the first year of independent walking: A dynamical systems analysis. Child Development, 64, 1143-1157.

Cormery, B., Marcil, M., \& Bouvard, M. (2008). Rule change incidence on physiological characteristics of elite basketball players: A 10-year-period investigation. British Journal of Sports Medicine, 42, $25-30$.

Courel-Ibáñez, J., McRobert, A. P., Toro, E. O., \& Vélez, D. C. (2017). Collective behaviour in basketball: A systematic review. International Journal of Performance Analysis in Sport, 17, 44-64.

Csataljay, G., O’Donoghue, P., Hughes, M., \& Dancs, H. (2009). Performance indicators that distinguish winning and losing teams in basketball. International Journal of Performance Analysis in Sport, 9, 60-66.

Dadelo, S., Turskis, Z., Zavadskas, E. K., \& Dadeliene, R. (2014). Multi-criteria assessment and ranking system of sport team formation based on objective-measured values of criteria set. Expert Systems with Applications, 41, 6106-6113.

Doğan, İ., Işik, Ö., \& Ersöz, Y. (2016). Examining the Turkish men's professional basketball team's success according to game-related statistics with discriminant analysis. International Journal of Performance Analysis in Sport, 16, 829-836.

Erculj, F., \& Strumbelj, E. (2015). Basketball shot types and shot success in different levels of competitive basketball. PLoS One, 10, e0128885. doi:10.1371/journal.pone.0128885

Ferreira, A. P., Volossovitch, A., \& Sampaio, J. (2014). Towards the game critical moments in basketball: A grounded theory approach. International Journal of Performance Analysis in Sport, 14, 428-442.

Fewell, J. H., Armbruster, D., Ingraham, J., Petersen, A., \& Waters, J. S. (2012). Basketball teams as strategic networks. PloS one, 7, e47445.

Fotinakis, P., Laparidis, C., Karipidis, A., \& Taxildaris, K. (2002). Due pallacanestro a confronto. . SDS, 21, 52-56.

García, J., Ibáñez, S. J., Gómez, M. A., \& Sampaio, J. (2014). Basketball game-related statistics discriminating ACB league teams according to game location, game outcome and final score differences. International Journal of Performance Analysis in Sport, 14, 443-452. 
García, J., Ibáñez, S. J., Martinez De Santos, R., Leite, N., \& Sampaio, J. (2013). Identifying basketball performance indicators in regular season and playoff games. Journal of Human Kinetics, 36, 161168.

Gómez, M. A., Gasperi, L., \& Lupo, C. (2016). Performance analysis of game dynamics during the 4th game quarter of NBA close games. International Journal of Performance Analysis in Sport, 16, 249-263.

Gómez, M. A., Ibáñez, S., Parejo, I., \& Furley, P. (2017). The use of classification and regression tree when classifying winning and losing basketball teams. Kineziologija, 49, 12-13.

Gómez, M. A., Lorenzo, A., Ibanez, S. J., \& Sampaio, J. (2013). Ball possession effectiveness in men's and women's elite basketball according to situational variables in different game periods. Journal of Sports Sciences, 31, 1578-1587. doi:10.1080/02640414.2013.792942

Gómez, M. A., Lorenzo, A., Ortega, E., Sampaio, J., \& Ibáñez, S. J. (2009). Game related statistics discriminating between starters and nonstarters players in Women's National Basketball Association League (WNBA). Journal of Sports Science and Medicine, 8, 278-283.

Gómez, M. A., Lorenzo, A., Sampaio, J., Ibáñez, S. J., \& Ortega, E. (2008). Game-related statistics that discriminated winning and losing teams from the Spanish men's professional basketball teams. Collegium Antropologicum, 32, 451-456.

Gómez, M. A., \& Pollard, R. (2011). Reduced home advantage for basketball teams from capital cities in Europe. European Journal of Sport Science, 11, 143-148.

Gómez, M. A., Prieto, M., Perez, J., \& Sampaio, J. (2013). Ball possession effectiveness in men's elite floorball according to quality of opposition and game period. Journal of Human Kinetics, 38, 227-237. doi:10.2478/hukin-2013-0062

Guerra, Y. D. S., González, J. M. M., Montesdeoca, S. S., Ruiz, D. R., López, N. A., \& García-Manso, J. M. (2013). Basketball scoring in NBA games: An example of complexity. Journal of Systems Science and Complexity, 26, 94-103.

Hamill, J., van Emmerik, R. E., Heiderscheit, B. C., \& Li, L. (1999). A dynamical systems approach to lower extremity running injuries. Clinical Biomechanics, 14, 297-308.

Hoffman, J. R., Epstein, S., Einbinder, M., \& Weinstein, Y. (1999). The influence of aerobic capacity on anaerobic performance and recovery indices in basketball players. The Journal of Strength \& Conditioning Research, 13, 407-411.

Hopkins, W. G. (2007). A spreadsheet to compare means of two groups. Sportscience, 11, 22-24.

Hopkins, W. G., Marshall, S. W., Batterham, A. M., \& Hanin, J. (2009). Progressive statistics for studies in sports medicine and exercise science. Medicine \& Science in Sports \& Exercise, 41, 3-13. doi:10.1249/MSS.0b013e31818cb278

Hughes, M., \& Franks, I. M. (2004). Notational analysis of sport: Systems for better coaching and performance in sport. London: Routledge.

Ibáñez, S. J., Sampaio, J., Feu, S., Lorenzo, A., Gómez, M. A., \& Ortega, E. (2008). Basketball gamerelated statistics that discriminate between teams' season-long success. European Journal of Sport Science, 8, 369-372.

Ibáñez, S. J., Sampaio, J., Sáenz-López, P., Giménez, J., \& Janeira, M. (2003). Game statistics discriminating the final outcome of junior world basketball championship matches (Portugal 1999). Journal of Human Movement Studies, 45(1), 1-20.

Kerlinger, F. N. F. N., \& Pedhazur, E. J. (1973). Multiple regression in behavioral research. New York, NY: Holt, Rinehart and Winston.

Kiani Mavi, R., Kiani Mavi, N., \& Kiani, L. (2012). Ranking football teams with AHP and TOPSIS methods. International Journal of Decision Sciences, Risk and Management, 4, 108-126.

Kubatko, J., Oliver, D., Pelton, K., \& Rosenbaum, D. T. (2007). A starting point for analyzing basketball statistics. Journal of Quantitative Analysis in Sports, 3(3), 1-22.

Liu, H., Gómez, M. A., Gonçalves, B., \& Sampaio, J. (2016). Technical performance and match-tomatch variation in elite football teams. Journal of Sports Sciences, 34, 509-518.

Lorenzo, A., Gómez, M. A., Ortega, E., Ibáñez, S. J., \& Sampaio, J. (2010). Game related statistics which discriminate between winning and losing under-16 male basketball games. Journal of Sports Science and Medicine, 9, 664-668. 
Marcelino, R., Mesquita, I., \& Sampaio, J. (2011). Effects of quality of opposition and match status on technical and tactical performances in elite volleyball. Journal of Sports Sciences, 29, 733-741. doi: $10.1080 / 02640414.2011 .552516$

Mateus, N., Gonçalves, B., Abade, E., Liu, H., Torres-Ronda, L., Leite, N., \& Sampaio, J. (2015). Gameto-game variability of technical and physical performance in NBA players. International Journal of Performance Analysis in Sport, 15, 764-776.

Miller, S. (2002). Variability in basketball shooting: Practical implications. In Y. Hong (Ed.), International research in sports biomechanics (pp. 27-34). London: Routledge.

Miller, S., \& Bartlett, R. (1994). Notational analysis of the physical demands of basketball. Journal of Sports Sciences, 12, 181-182.

Newell, K. M., \& Corcos, D. M. (1993). Variability and motor control. Champaign, IL: Human Kinetics.

O'Donoghue, P. (2005). Normative profiles of sports performance. International Journal of Performance Analysis in Sport, 5, 104-119.

O’Donoghue, P. (2013). Statistics for sport and exercise studies: An introduction. Abingdon, OX: Routledge.

Oliver, D. (2004). Basketball on paper: Rules and tools for performance analysis. Washington, DC: Potomac Books.

Ostojic, S. M., Mazic, S., \& Dikic, N. (2006). Profiling in basketball: Physical and physiological characteristics of elite players. The Journal of Strength \& Conditioning Research, 20, 740-744.

Paul, M., \& Garg, K. (2012). The effect of heart rate variability biofeedback on performance psychology of basketball players. Applied Psychophysiology and Biofeedback, 37, 131-144.

Pinilla Arbex, J., Pérez Tejero, J., Van Biesen, D., \& Vanlandewijck, Y. (2015). Performance variability in basketball players with intellectual impairment: Ankara World Championships 2013 analysis. Revista de psicología del deporte, 24, 77-83.

Pollard, R., \& Gómez, M. A. (2007). Home advantage analysis in different basketball leagues according to team ability. Iberian Congress on Basketball Research, 4, 61-64.

Pollard, R., \& Gómez, M. A. (2013). Variations in home advantage in the national basketball leagues of Europe. Revista de Psicología del Deporte, 22, 263-266.

Robins, R., Wheat, J., Irwin, G., \& Bartlett, R. (2006). The effect of shooting distance on movement variability in basketball. Journal of Human Movement Studies, 50, 217-238.

Sallet, P., Perrier, D., Ferret, J., Vitelli, V., \& Baverel, G. (2005). Physiological differences in professional basketball players as a function of playing position and level of play. Journal of Sports Medicine and Physical Fitness, 45, 291-294.

Sampaio, J., Drinkwater, E. J., \& Leite, N. M. (2010). Effects of season period, team quality, and playing time on basketball players' game-related statistics. European Journal of Sport Science, 10, 141-149. doi:10.1080/17461390903311935

Sampaio, J., Ibáñez, S. J., Gómez, M. A., Lorenzo, A., \& Ortega, E. (2008). Game location influences basketball players performance across playing positions. International Journal of Sport Psychology, $39,43-50$.

Sampaio, J., Ibáñez, S. J., Lorenzo, A., \& Gómez, M. A. (2006). Discriminative game-related statistics between basketball starters and nonstarters when related to team quality and game outcome. Perceptual and Motor Skills, 103, 486-494.

Sampaio, J., \& Janeira, M. (2003). Statistical analyses of basketball team performance: Understanding teams' wins and losses according to a different index of ball possessions. International Journal of Performance Analysis in Sport, 3, 40-49.

Sampaio, J., Janeira, M., Ibáñez, S. J., \& Lorenzo, A. (2006). Discriminant analysis of game-related statistics between basketball guards, forwards and centres in three professional leagues. European Journal of Sport Science, 6, 173-178. doi:10.1080/17461390600676200

Sampaio, J., Lago, C., Casais, L., \& Leite, N. (2010). Effects of starting score-line, game location, and quality of opposition in basketball quarter score. European Journal of Sport Science, 10, 391-396.

Sampaio, J., McGarry, T., Calleja-Gonzalez, J., Jimenez Saiz, S., Schelling, I. D. A. X., \& Balciunas, M. (2015). Exploring game performance in the national basketball association using player tracking data. PLoS One, 10, e0132894. doi:10.1371/journal.pone.0132894 
Steenland, K., \& Deddens, J. A. (1997). Effect of travel and rest on performance of professional basketball players. Sleep, 20, 366-369.

Stergiou, N., \& Decker, L. M. (2011). Human movement variability, nonlinear dynamics, and pathology: Is there a connection? Human Movement Science, 30, 869-888.

Stergiou, N., Harbourne, R. T., \& Cavanaugh, J. T. (2006). Optimal movement variability. Journal of Neurologic Physical Therapy, 30, 120-129.

Thelen, E. (1995). Motor development: A new synthesis. American Psychologist, 50, 79-95.

Tomovic, M., Batinic, D., Saranovic, S. D., \& Antic, M. (2016). P-91 Anthropometric features of elite male basketball players regarding their playing position. Can a high BMI be a health risk for this group of athletes? British Journal of Sports Medicine, 50 (Suppl 1), 82.

Trninić, S., Papić, V., Trninić, V., \& Vukičević, D. (2008). Player selection procedures in team sports games. Acta Kinesiologica, 2, 24-28.

Tsitskaris, G., Theoharopoulos, A., \& Garefis, A. (2003). Speed, speed dribble and agility of male basketball players playing in different positions. Journal of Human Movement Studies, 45, 21-30.

van Beers, R. J., Haggard, P., \& Wolpert, D. M. (2004). The role of execution noise in movement variability. Journal of Neurophysiology, 91, 1050-1063.

Willoughby, D. S., \& Simpson, S. (1996). The effects of combined electromyostimulation and dynamic muscular contractions on the strength of college basketball players. The Journal of Strength \& Conditioning Research, 10, 40-44. 